\title{
Geometric Consideration of Support Structures in Part Overhang Fabrications by Electron \\ Beam Additive Manufacturing
}

\author{
Bo Cheng, Kevin Chou \\ Department of Mechanical Engineering \\ The University of Alabama \\ Tuscaloosa, AL 35487
}

\begin{abstract}
Powder bed electron beam additive manufacturing (EBAM) has emerged as a potentially cost-effective process for high-value, small-batch productions for biomedical and aerospace applications. In EBAM, the process would not require support structures for overhang geometry because a build part is immersed in the powder bed. However, support structures are indeed needed in practice for an overhang; without it, the overhang area will have defects such as warping, which are due to the complex thermomechanical process in EBAM. In this study, a numerical approach is introduced to simulate the thermomechanical responses in the EBAM process of overhang structures. The objective of this study was to develop a 2D thermomechanical model, using a finite element method (FEM), to evaluate temperature induced deformation on different overhang support patterns in the EBAM process. The major results are summarized as follows. (1) The thermomechanical model is able to simulate the deformation of overhang parts in EBAM. The overhang length noticeably affects the overhang deformation. (2) As a traditional support structure, solid columns can reduce the overhang warping; further, the size of the column may be minimized to satisfy a deformation constraint, and meanwhile, reduce the amount of support materials. (3) Including a solid piece beneath the overhang, acting as a heat sink, may also reduce the overhang deformation; however, an appropriate gap must be incorporated so not to fuse to the overhang area, while still effectively reducing the deformation. Keywords: Electron beam additive manufacturing (EBAM); Overhang; Support structures; Ti6Al-4V; Thermomechanical analysis; Deformation
\end{abstract}




\section{Introduction}

Additive manufacturing (AM) based on "layer-adding" fabrications is a group of technologies, by which a physical solid part is produced directly from digital data of the part geometric model. This group of technologies offers many design and manufacturing advantages such as short lead time, design freedom in geometry, and tooling-free productions. Powder-based electron beam additive manufacturing (EBAM) is a relatively new AM technology [1]; it utilizes a high-energy electron beam, as a moving heat source, to melt and fuse metal powder and produce a solid part in a layer-by-layer fashion. The process detail can be found in literature [2]. EBAM is one of a few AM technologies capable of making full-density metallic parts, which drastically broaden AM applications in a wide variety of industries [1,3].

Because of the high energy density, EBAM has the potential to work with many material classes, e.g., aluminum alloys [4], tool steel [5], cobalt-based superalloys [6], $\mathrm{Cu}$ [7], and Inconel alloys [8], etc. One titanium alloy, Ti-6Al-4V, was the first material extensively researched [9, 10], also widely used, in EBAM technologies for aircraft parts and medical implants. Moreover, Intermetallic groups such as titanium aluminide have also been studied for EBAM applications, but the process development was considered very time consuming [11]. Another intriguing EBAM capability is to fabricate complex geometries and structures (e.g., meshed, porous, cellular).

Although there is an increasing interest in study EBAM process recently, the primary focuses are different materials applications, build part microstructure and properties. For the EBAM process numerical simulation, Zäh and Lutzmann [12] developed a simplified heat transfer model to study the melt pool geometry based on a finite element method (FEM) in the EBAM process. Mahale [13] utilized both a FEM and a finite difference method to develop a 3D model in COMSOL Multiphysics for simulation of the EBAM process of Al 7075. Jamshidinia et al. [14] developed a thermal-fluid flow model of EBAM incorporating powder thermal properties to study the influence of process parameters and melt pool flow convection effect. However, these modeling works are mainly focused on the thermal responses of the EBAM process.

In the field of thermomechanical simulation, there is a pool of process modeling literature for the laser-based metal AM. In a multi-layer laser Direct Metal Deposition (DMD) process, Liu et al. [15] have presented a 3D sequentially coupled thermomechanical FEM model to predict 
residual stresses and deformations. The temperature, residual stress, and deflections have been explored. Based on simulations, the cooling rate in DMD process can be as high as $3000 \mathrm{~K} / \mathrm{s}$. In addition, stress distributions along $\mathrm{x}, \mathrm{y}, \mathrm{z}$ directions have been investigated. The model prediction ability has been verified by experimental value. In a Selective Laser Melting (SLM) process, Zaeh and Branner [16] studied the effect of layer thickness on t-shaped cantilever part deformation using a 3D thermomechanical model. The simulation results indicated that smaller layer thickness sizes were responsible for larger deformations since the inserted energy had to be distributed into reduced layer volumes. Dai and Shaw [17] numerically investigated the effect of laser scanning strategy on residual thermal stresses and distortion of a flat nickel plate in ANSYS. The findings revealed that proper laser scanning patterns could result in less out-of-plane distortion. Nickel et al. [18] presented a 3D numerical study on deposition pattern of laser deposited metal parts produced by the shape deposition manufacturing (SDM). The results clearly pointed out that the deposition pattern had a significant effect on the part deflection. Specifically, a raster pattern with lines oriented 90 degrees from the beam's long axis produced the lowest deflections for a beam substrate, while the spiral pattern scanned from the outside to the inside produced low and uniform deflections for a plate geometry. Matsumoto et al [19] has proposed a FEM study for calculating the distribution of temperature and stress within a single metallic layer formed on the powder bed in SLM process. Results showed that the stress distribution displayed a stripe pattern of compressive and tensile stresses in the solidified part. The deflection of the solid layer increased as the track length increased. In addition, a large tensile stress occurred at the side end of the solid part when the neighboring track began to solidify. In order to prevent part deficiency, they suggested that it was better to divide the area into small regions with strong frames and use short track scanning in each region.

One the other hand, thermomechanical modeling of the EBAM process is only sparsely found in literature. Jamshidinia et al. [20] developed a coupled Computational Fluid Dynamic (CFD) - FEM model to study the heat and thermal stress distribution in electron beam melting process. Their simulation results showed that the formation of an outward flow in the melt pool of Ti-6Al-4V could be caused by negative temperature coefficient of surface tension. Their study also indicated that electron beam scanning speed would have influence on the thermal stresses, specifically, the minimum electron beam scanning speed of $100 \mathrm{~mm} / \mathrm{s}$ resulted in the maximum thermal stress in melting step and minimum thermal stresses in cooling step. 
One of the advantages in AM technologies is freedom in part geometry designs. However, for some AM processes, e.g., the material extrusion type AM, also known as fused deposition modeling (FDM), part designs with overhang (or undercut) geometry are considered not favorable. In such an AM process, a part overhang will require the so-called "support structure" to carry the weight of the overhang portion. However, the support structure has to be removed during post-processing, which may be time consuming and add additional production cost. Hence, overhang geometry may be considered as undesired design geometries. Some approaches have been used to tackle support structure removals, e.g., designing break-away structures or using water solvable materials in FDM. On the other hand, powder-bed-fusion AM processes including EBAM are considered not requiring a support for an overhang because the powder bed itself is able to bear the weight of a built overhang. However, in common practices, still, the general rule is to arrange support structures underneath an overhang, or defects such as warping may occur. Defects such as warping associated with overhang geometry problems in EBAM have not been frequently studied in literature. Recently, Vora et al. [21] attempted to benchmark the problems with overhangs and reported cases that overhang warping occurs.

For laser-based powder bed AM processes such as selective laser sintering or melting (SLS or SLM), there are a few studies related to support structures in literature. The focus was, however, on the design and fabrication of support structures. Jihabvala et al. [22] reported using pulse laser, instead of a continuous mode, to fabricate support structures and claimed the fabricated supports are much easier to be removed. Yan et al. [23] studied "cellular lattice" structures for support and investigated the effect of cellular geometry parameters. The evaluation criterion was the ease of removal and access. The authors also intended to use cellular-type support to minimize the material volume needed for support. In general, the above mentioned studies have not comprehensively addressed the aspect of the need of supports for an overhang and for suitable support types.

EBAM has a potential to be a cost-effective alternative to conventional discrete component manufacture for high-value, small-batch, and custom-designed metallic parts. However, one of the challenges in part designs is inevitable overhang geometries. The overhang area will require support structures, or there will be defects around the overhang area, shown in Figure 1, including size inaccuracy and, most noticeably, distortions. Furthermore, postprocessing for support removal can be labor intense and time consuming. There are commercial 
software packages, e.g., [24], which can generate support structures with a variety of options (patterns/size); however, there is no clear guideline of support design, relying on trial and error and experiences. Moreover, it needs to be pointed out that those support designs were developed more for the weight-carrying purpose, to avoid overhang area deformation due to gravity. It does not address the powder bed conditions for the process like EBAM. Moreover, additional questions are: what is the root cause of overhang defects, and what type of "support" configurations will function to minimize warping defects, and yet, without burdening postprocessing?

To effectively design necessary supports, it is essential to understand the source of defects associated with overhang geometries in EBAM. It is argued that for EBAM, heat load, instead of gravity load, is more the source of the problems. Because the powder bed (with sintered powder) has a far poor thermal conductivity compared to a solid, and thus, heat dissipation around the overhang area may be less efficient compared to an area with a solid substrate. The assumption of overhang defect causes, therefore, is that in the powder area beneath an overhang, the ineffective heat dissipation, repeated thermal gradient cycles and the shrinkage of deposited layers result in warping defects. Hence, the research needs would be a fundamental thermomechanical study of EBAM for distortion evaluations. The knowledge obtained may be applied to facilitate investigations of different overhang configurations, thermal and mechanical responses, and to enable effective designs for heat load supports and simultaneously for ease of support structure removals.

In this study, a 2D FEM model, incorporating Gaussian heat flux distribution, latent heat of fusion and temperature dependent material properties, was developed to study the thermomechanical response when subject to a moving heat source of high intensity. The model can be used to study the temperature induced deformation in fabricating overhang parts with different support structures in the EBAM process. By utilizing the thermomechanical model, it is possible to improve the quality of EBAM parts through effective support structures.

\section{Finite Element Modeling}

\subsection{Thermal analysis}

The temperature distribution of the EBAM process is given by the heat conduction governing equation as follows: 


$$
\nabla\left(\frac{k_{(T)}}{\rho_{(T)} c_{(T)}} \nabla T\right)+\frac{\dot{Q}_{(x, y, z, T)}}{\rho_{(T)} c_{(T)}}=\frac{\partial T}{\partial t}+v_{s} \frac{\partial T}{\partial x},
$$

where $T$ is temperature, $\dot{Q}_{(x, y, z, T)}$ is the absorbed heat flux, $\rho$ is density, $k$ is thermal conductivity, $c$ is specific heat capacity, $v_{s}$ is the constant speed in the x-direction of the moving electron beam heat source. Moreover, the material properties $c, \rho$ and $k$ are temperature dependent.

In order to consider the phase transformation of the physical process, the latent heat of fusion, $L_{f}$, was included in the mathematical model. The latent heat of fusion was modeled as an additional term of the internal thermal energy per unit mass, $d U$, when the temperature reaches the region between the solidus and liquidus points, $T_{S}$ and, $T_{L}$, respectively. Hence, the enthalpy is defined as:

$$
H(T)=\int c d T+L_{f} f,
$$

where $f$ is the liquid volumetric fraction, which is defined as:

$$
f= \begin{cases}0 & T<T_{S}, \\ \frac{T-T_{S}}{T_{L}-T_{S}} & T_{S} \leq T \leq T_{L}, \\ 1 & T>T_{L}\end{cases}
$$

A moving conical volumetric heat source, which has a Gaussian distribution in the $\mathrm{x}-\mathrm{y}$ plane with the intensity varies along the depth direction (z-direction), is modeled to simulate the electron beam heat source and incorporated in a user subroutine of DFLUX. The heat source was represented as Eqn. (4), which is modified from Zäh and Lutzmann [12]; the heat intensity decreases with the increase of the penetration depth [12],

$$
\dot{Q}_{(x, y, z)}=\eta \times \frac{H_{s} \times I_{z}}{S}
$$

with

$$
\begin{aligned}
& I_{z}=\frac{1}{0.75}\left(-2.25\left(\frac{z}{s}\right)^{2}+1.5\left(\frac{z}{s}\right)+0.75\right), \\
& H_{S}=\frac{2 U I_{b}}{\pi \Phi_{\mathrm{E}}^{2}} \exp \left\{-\frac{2\left[\left(x-x_{S}\right)^{2}+\left(y-y_{s}\right)^{2}\right]}{\Phi_{\mathrm{E}}^{2}}\right\} .
\end{aligned}
$$

in which the parameters include electron beam absorption efficiency coefficient: $\eta$, voltage: $U$, current: $I_{b}$, penetration depth: $S$, and beam diameter: $\Phi_{E}$. The $x_{S}$ and $y_{S}$ are the 
instantaneous horizontal position of the heat source center. The 3D heat source equation can be determined by combining the Gaussian heat source $H_{s}[25]$ and the penetration function $I_{z}$.

However, only $\mathrm{x}-\mathrm{y}$ plane is modeled and scanned by the heat source since this study is focused on 2D model. The heat source is moving along the $\mathrm{x}$-direction at a constant speed, and the $\mathrm{z}$ coordinate is replaced by y coordinate. Thus Eq. (4) becomes the following:

$$
\dot{Q}_{(x, y)}=\eta \times \frac{H_{s} \times I_{y}}{S}
$$

with

$$
\begin{aligned}
& I_{y}=\frac{1}{0.75}\left(-2.25\left(\frac{y}{s}\right)^{2}+1.5\left(\frac{y}{s}\right)+0.75\right), \\
& H_{S}=\frac{2 U I_{b}}{\pi \Phi_{\mathrm{E}}^{2}} \exp \left\{-\frac{2\left[\left(x-x_{s}\right)^{2}\right]}{\Phi_{\mathrm{E}}^{2}}\right\}
\end{aligned}
$$

\subsection{Structural analysis}

During the electron beam scanning process, the rapid heating and cooling process is localized and large temperature gradient is expected to occur over a small area. Due to resulted thermal gradients, thermal stresses and distortions may be generated in the build part. The governing equations, used to describe the relationship between temperature and the corresponding thermal strain as well as stress, is [26]:

$$
\begin{aligned}
& \{\varepsilon\}=[D]^{-1}\{\sigma\}+\left\{\varepsilon^{t h}\right\} \\
& \left\{\varepsilon^{t h}\right\}=\alpha_{e} \times \Delta T=\alpha_{e}\left(T-T_{\text {ref }}\right) \\
& \{\sigma\}=[D]\{\varepsilon\},
\end{aligned}
$$

where $\{\varepsilon\}$ is the total strain, $\left\{\varepsilon^{t h}\right\}$ is the thermal strain, $\alpha_{e}$ is the coefficient of expansion, $T$ is the incident temperature, $T_{r e f}$ is the reference temperature, $[D]$ is the stressstrain matrix, and $\{\sigma\}$ is the stress matrix.

\subsection{Material properties modeling}

The material considered in this study was Ti-6Al-4V, its material properties, including both thermal and mechanical, temperature dependent, were from literature studies. Temperature dependent thermal properties of solid Ti-6Al-4V alloy have been reported: density [27, 28], specific heat [29]. In a recent study [30], the thermal conductivity of Ti-6Al-4V solid and sintered powder with $50 \%$ porosity were experimentally measured, from samples built by an ARCAM S12 machine, at different temperatures (up to $750{ }^{\circ} \mathrm{C}$ ). It has been noticed that the thermal conductivity of the Ti-6Al-4V sintered powder was much smaller than the solid 
counterpart, e.g., $0.63 \mathrm{~W} / \mathrm{m} \cdot \mathrm{K}$ vs. $6.2 \mathrm{~W} / \mathrm{m} \cdot \mathrm{K}$ at $25^{\circ} \mathrm{C}$. Thermal conductivity values at different temperatures were obtained, for material in single state (solid or sintered powder), through a linear interpolation method with the experimental data [30]. Material state transition from sintered powder to solid has been considered by another user subroutine of UMATHT. Whenever the material has been updated from sintered powder to solid, it will have solid conductivity immediately. Increased thermal conductivity above the melting point was used to account for heat convection phenomenon in the melt pool during melting [30, 31]. Material temperature dependent mechanical properties are obtained from Huang et al [32]. The emissivity of Ti-6Al-4V used in the model was estimated as 0.7 from Yang et al. [27]. An isotropic kinematic hardening model is used without considering the modeling of complex viscoplastic behavior. All the material properties are summarized in Figure 2, and were utilized in the thermomechanical model.

\subsection{Numerical model configuration}

A 2D FEM thermomechanical model is developed by using ABAQUS to simulate the temperature induced deformation in a multi-layer deposition process of an overhang structure. Figure 3-a shows the geometric details for a typical overhang model, which has a substrate placed in powder bed. The powder material is Ti-6Al-4V powder (sintered) with $50 \%$ porosity. A thin layer, on the top of the substrate, is assumed to be the latest added powder layer, which also has the powder properties. In this study, a total of 3 layers will be deposited sequentially above substrate. A conical body heat source with linearly decaying along y-direction (building direction), and scanning along x-direction, has been applied on the top powder layer, shown in Figure 3-b.

The major analysis step is consisted of preheating cycle, electron beam scanning/melting cycle and cooling cycle. The beam preheating cycle is simplified as the thermal initial conditions for both substrate and powder layer, and then assigned with a uniform temperature distribution of $\mathrm{T}_{\text {preheat }}$. Electron beam moving and heating will be initiated at the scanning/melting cycle. Due to vacuum working environment, convection between the powder layer and surroundings is ignored, only the radiation is considered in the heat transfer between the part and environment. The temperature of substrate bottom is confined as a constant temperature of $\mathrm{T}_{\text {preheat }}$ as the thermal boundary condition. The electron beam scanning occurs at the top surface of a powder layer and traverses along the $\mathrm{x}$-axis with a constant speed. In the center of the electron beam 
when temperature exceeds the evaporating point, the node is set to be remained in the mesh. All the mechanical Degrees of Freedom (DOFs) are confined at the bottom of the solid substrate since the bottom was constrained by steel plate. Figure 3-b shows all the applied thermal and mechanical boundary conditions in scanning/melting cycle.

After the scanning/melting phase, the simulation of the cooling phase was followed. There are two cooling steps in the EBAM process. The first cooling step is in the melting phase which is actually the part temperature self-balancing corresponding to a few seconds interval before a new powder layer spreading. The time is assumed as 10 seconds, which is approximately the duration for the next powder layer spreading during the EBAM process. The second cooling step is the final cooling; all the materials are assumed to be simply under cooling process until the temperature drops to the room temperature of $20{ }^{\circ} \mathrm{C}$. The displacement constraints at the bottom surface of solid substrate are kept due to the same aforementioned bonding issue. The thermal boundary condition is pure radiation on the top surface; the confined bottom temperature boundary condition is removed.

The element activation method is applied to simulate the powder layer addition process in this multi-layer deposition simulation. The second and following powder layers have been modeled at the beginning, but deactivated in the scanning/melting phase of the first layer. The second and following powder layers will be reactivated at corresponding melting phases. During each reactivation process, the bottom temperature is still kept as the $\mathrm{T}_{\text {preheat }}$ and the surface radiation boundary condition will be deactivated for the previous layer while activated for the newly deposited layer. Then, the beam scanning process starts again from the same starting point on the top powder layer. Detailed modeling parameters are listed in Table 1. Figure 4-a shows the flow chart of numerical procedure of the developed model, Figure 4-b presents the multilayer deposition and simulation process.

Coupled temperature-displacement elements (CPE4T) were used for the whole model. A finer mesh was applied in the beam scanning path to directly incorporate the incident Gaussian beam heat flux region while coarser mesh was used in regions away from high beam energy affected zone. The advantages of this meshing method were to save computational time and maintain good model accuracy. The element size in the scanning area was $100 \mu \mathrm{m} \times 35 \mu \mathrm{m}$ $(x \times y)$ with the mesh size gradually increased with the distance away from the primary scanning 
area. The typical computational time for one simulation case is around 20 hours using two Inter(R) Xeon(R) E5 CPUs.

\section{Overhang and Support Structure Simulation Study}

The distortion phenomenon in the EBAM process can be explained by temperature induced deformation mechanism [35]. Due to the rapid heating of the upper surface by the fast moving electron beam and the comparatively slow heat conduction, a steep temperature gradient develops. Then the underlying material, which has a lower temperature, restricts the expansion of the heated deposited layers and counter compressive strains are induced. Therefore, without mechanical constraints on the top surface, a counter bending away from the electron beam can be expected. In the cooling period, the compressed deposited layers start shrinking and a bending angle towards the beam develops. Figure 5 shows the temperature induced deformation mechanism.

During the powder deposition process, the newly deposited material is automatically placed above the powder bed. Therefore, the inefficient heat dissipation around the overhang area, caused by poor thermal conductivity, and the shrinkage of the deposited layers may lead to warping defects. An initial FEM study has been conducted to investigate the overhang warping. A model with a 2-layer deposition process, based on Figure 3, has been constructed for this thermomechanical simulation study. It has a substrate dimension of $16 \times 10 \mathrm{~mm}$ (Length $\times$ Height) consisting of half powder and half solid.

Two cases with different substrate types have been investigated in order to evaluate the overhang effect. One (Case A) is the solid substrate case; while the other (Case B) is the half solid and half powder substrate (overhang) case. For the overhang region above the powder bed, it can be expected that a larger warping would occur due to higher max temperature, e.g., 2980 ${ }^{\circ} \mathrm{C}$ of Case B and $\sim 2940{ }^{\circ} \mathrm{C}$ of Case A, as shown in Figure 6. Their stress contour plots along the scanning direction (x-direction) after the final part cooling (to room temperature of $20{ }^{\circ} \mathrm{C}$ ) have been shown in Figure 7-a and b. The surrounding powder has not been shown in both cases since the major area of focus is the scanning region. The deposited top layers have shrinkage stresses that lead to warping. In addition, due to the smaller solid substrate area for Case B, the warping above the solid substrate could be reduced. The top surface deflection profiles for both cases are shown in Figure 7-c. The results clearly illustrate the warping trend as discussed: Case B has a 
larger warping defect above the powder substrate while a smaller deformation is shown above the solid substrate.

According to the above simulated results, the overhang structure can result in a serious part warping problem. Therefore, improved designs of overhang geometry (e.g., support features) may help to reduce the distortion of the overhang area. The numerical model can be a cost-effective way to study thermomechanical responses of different overhang support features when subject to a moving heat source. Three types of overhang structures, each with different control dimensions and support features, have been constructed based on Figure 3. Their structural configurations are shown in Figure 8; in which the parameters are: $\mathrm{L}$ is the overhang length; Wc is the width of the support column; Gap is the distance between bottom surface of the first deposited layer and the top surface of the solid piece (solid Ti-6Al-4V material). For all the cases, there are a total of three deposited top layers above the substrate. Figure 8-a shows the configuration of the overhang length effect model, L will be 5,10,15 and $25 \mathrm{~mm}$. The solid column model $(\mathrm{L}=15 \mathrm{~mm})$ is shown in Figure 8-b. The bottom surface of the column will be fully constrained. The width, Wc, will have three values of $0.5,1.0$ and $1.5 \mathrm{~mm}$. A solid piece under the deposited layers may improve the heat dissipation due to the increase of conductivity

in the powder substrate. However, the gap between the solid piece and the deposited layers may present an issue since the gap distance will affect the heat transfer between the deposited layers and the solid piece. Figure 8-c describes the gap effect model configuration ( $\mathrm{L}=15 \mathrm{~mm})$, the gap distances will be $0,0.63$ and $6.3 \mathrm{~mm}$.

\section{Results and Discussion}

\subsection{Overhang length effect}

One typical example of part warping after final cooling of the 3-layer deposition for the $15 \mathrm{~mm}$ overhang length case is shown in Figure 9-a. The surrounding powder has not been shown in order to improve the illustration of the overhang deformation. The aforementioned temperature induced deformation mechanism can also be applied here. Due to a full constraint of the bottom surface of the solid substrate, no deformation is shown around the bottom region; the deformation magnitude continues to increase along the building direction. The largest deformation appears around the right region of the overhang area. 
To better understand the overhang length effect, a set of simulations with different overhang lengths ( $\mathrm{L}=5 \mathrm{~mm}, 10 \mathrm{~mm}, 15 \mathrm{~mm}$ and $25 \mathrm{~mm}$, respectively) have been completed. The top surface deformations (along the scanning path) have been plotted in Figure 9-b, which clearly indicate that a larger deformation will be caused by a longer overhang length. Therefore, a short overhang length should be used in the building process to reduce part warping if no additional support structure is applied.

\subsection{Support column effect}

Figure 10-a displays final deformation contours for a support column $(\mathrm{Wc}=1.0 \mathrm{~mm})$ case. There is no deformation in the bottom region of the support column due to a fully constrained boundary condition. Top surface deformation plots from the $\mathrm{Wc}=1.0 \mathrm{~mm}$ case and the $\mathrm{L}=15 \mathrm{~mm}$ case have been compared. An expected deformation drop for the $\mathrm{Wc}=1.0 \mathrm{~mm}$ case can be noted as a result of the applied support column constraint, illustrated in Figure 10-b.

To reduce build cost, it is necessary to investigate the amount of material used in the support columns and the corresponding effect on warping reduction. In the 2D simulation, the amount of material used in support columns is proportional to the width of the column. The $\mathrm{Wc}=0.5 \mathrm{~mm}$ column width is considered the "base size" for future comparison, and the increment of support column material usage (column width) is set to be $1 \times$ "base size" at a time in simulation. Top surface deformation plots, from simulated results of different amounts of support column material usage cases (Wc values), have been concluded in Figure 11. However, the deformation is barely changed even if a larger amount of materials have been used, e.g., $\mathrm{Wc}=1.5 \mathrm{~mm}$ case $(3 \times$ "base size") vs. Wc=0.5 mm case ( $1 \times$ "base size"). The results confirm that even a thin support column, which requires less material, could provide mechanical constraint to prevent overhang curling. Thus, it is probably not necessary to spend a large amount of materials on building thick support columns.

\subsection{Solid piece gap effect}

Figure 12 presents a deformation contour after the final cooling for a solid piece (Gap = $0.63 \mathrm{~mm}$ ) case. Although a solid piece has been inserted under the deposited top layers, the overhang area still has a larger deflection than the solid area, as shown in Figure 12-a. However, a noticeable deformation drop, based on the top surface deformation information, can be observed in Figure 12-b when compared with the $\mathrm{L}=15 \mathrm{~mm}$ case. The inserted solid material in powder bed, with larger density and higher conductivity, can improve the effective thermal 
conductivity in the same heat affected region since the total energy input remains unchanged. Therefore, the solid piece would contribute to bring down the top surface temperature as well as the powder bed temperature. Temperature plots at different EBAM process steps have indicated that the solid piece can successfully reduce temperature, as shown in Figure 13. Figure 13-a shows temperature contours before the start of layer- 3 addition process, which is actually at the end of 10 seconds inter-layer cooling period between layer-2 and layer-3. The contours in the solid piece region shows a lower temperature than the corresponding region in the $\mathrm{L}=15 \mathrm{~mm}$ (no solid piece) case. The collected powder bed top surface temperature of the solid piece (Gap = $0.63 \mathrm{~mm}$ ) case is lower than that of the $\mathrm{L}=15 \mathrm{~mm}$ case as well. In the electron beam scanning/melting process (on layer-3), the powder bed temperature of the solid piece ( $\mathrm{Gap}=0.63$ $\mathrm{mm}$ ) case is also lower than that of the $\mathrm{L}=15 \mathrm{~mm}$ case, as shown in Figure 13-b. Figure 13-c indicates that the top layer surface temperature has been reduced by the solid piece in electron beam scanning process (on layer-3). Therefore, the minimization of deposited layers' max temperature and final cooling temperature $\left(20^{\circ} \mathrm{C}\right)$ by inserted solid piece can lead to final overhang deformation drop (i.e., $\alpha_{e} \times \Delta \mathrm{T}$ ).

It is also quite interesting to explore the effect of gap distance between the solid piece and deposited layers. The solid piece may have little effect on deformation reduction when a large gap distance is applied. The top surface deformation plot indicates that Gap $=6.3 \mathrm{~mm}$ case has a similar warping trend with no solid piece case ( $L=15 \mathrm{~mm}$ case), noticed in Figure 14. On the other hand, the smallest warping is obtained when the solid piece is directly placed under deposited layers, which is the Gap $=0 \mathrm{~mm}$ case. The deformation plot of Gap $=0.63 \mathrm{~mm}$ case is between Gap = 0 and $6.3 \mathrm{~mm}$ cases. Therefore, it can be concluded that the gap effect on the overhang warping reduction will be effective when a small gap distance is applied, such as the Gap $=0.63 \mathrm{~mm}$ case based on the simulated results. However, the gap distance should be carefully decided since the solid piece can be melted and solidified together with top layers, when the depth of the melt pool is larger than the selected gap distance during the electron beam scanning process.

\section{Conclusions}

In this study, a 2D thermomechanical model, using FEM, was developed for overhang and support structure studies in the EBAM process. The model incorporated a moving heat 
source with a Gaussian volumetric intensity, Ti-6Al-4V powder as well as solid material temperature dependent properties and latent heat of fusion, etc. The element activation method was used to simulate the layer addition process. A few geometric considerations of the overhang and support structures were investigated in fabricating overhang parts using EBAM. The major findings can be summarized as follows:

(1) A thermomechanical code, FEM-based developed in this study, is able to simulate the deformation of overhang parts in EBAM. As expected, the overhang length affect the overhang deformation; the longer the overhang, the larger the deformation.

(2) A solid column, as a traditional support structure means, can reduce and possibly eliminate the overhang warping; moreover, the size of the column may be minimized to reduce the amount of support materials, while meeting a deformation constraint.

(3) In addition, using a solid piece beneath the overhang, a nontraditional approach, may also effectively reduce the overhang deformation. However, an appropriate gap distance needs to be analyzed in order to be effective for deformation reductions, while not fused to the overhang part.

The developed 2D model can only be used for the deformation trend prediction in the EBAM process due to a lack of experiment validation. Future study of this research will focus on the influence of powder material properties, e.g., size and porosity. In addition, the initial temperature for solid and powder substrate needs to be improved since a uniform temperature has been assigned for the two sections in this study. It is not clear whether the preheating temperature will be the same for solid/powder substrate when considering their different thermal properties, especially thermal conductivity.

\section{Acknowledgements}

This research is supported by NSF (CMMI 1335481), and is in collaboration with Marshall Space Flight Center (MSFC), Advanced Manufacturing Team. The first author also acknowledges the scholarship support from the Alabama EPSCoR Graduate Research Scholars Program. 


\section{Reference}

[1] Gong, X., Anderson, T., and Chou, K., 2012, "Review on Powder-Based Electron Beam Additive Manufacturing Technology," ASME/ISCIE 2012 International Symposium on Flexible Automation, St. Louis, MO, June 18-20, 2012, ISFA2012-7256.

[2] Gaytan, S. M., Murr, L. E., Medina, F., Martinez, E., Lopez, M. I., and Wicker, R. B., 2009, "Advanced metal powder based manufacturing of complex components by electron beam melting," Materials Technology, 24, pp. 180-190.

[3] Biamino, S., Penna, A., Ackelid, U., Sabbadini, S., Tassa, O., Fino, P., Pavese, M., Gennaro, P., and Badini, C., 2011, "Electron beam melting of Ti-48Al-2Cr-2Nb alloy: Microstructure and mechanical properties investigation," Intermetallics, 19(6), pp. 776-781.

[4] Yu, P., Qian, M., Tomus, D., Brice, C. A., Schaffer, G. B., and Muddle, B. C., "Electron beam processing of aluminium alloys," Proc. Materials Science Forum, Trans Tech Publ, pp. 621-626.

[5] Cormier, D., Harrysson, O., and West, H., "Characterization of H13 steel produced via electron beam melting," Proc. Selected Papers from the 14th Annual Solid Freefrom Fabrication Symposium, University of Texas, Austin, Tesas, 4-6 August 2003, Emerald Group Publishing Ltd., pp. 35-41.

[6] Gaytan, S. M., Murr, L. E., Martinez, E., Martinez, J. L., MacHado, B. I., Ramirez, D. A., Medina, F., Collins, S., and Wicker, R. B., 2010, "Comparison of microstructures and mechanical properties for solid and mesh cobalt-base alloy prototypes fabricated by electron beam melting," Metallurgical and Materials Transactions A: Physical Metallurgy and Materials Science, 41(12), pp. 3216-3227.

[7] Ramirez, D. A., Murr, L. E., Martinez, E., Hernandez, D. H., Martinez, J. L., Machado, B. I., Medina, F., Frigola, P., and Wicker, R. B., 2011, "Novel precipitate-microstructural architecture developed in the fabrication of solid copper components by additive manufacturing using electron beam melting," Acta Materialia, 59(10), pp. 4088-4099.

[8] Murr, L., Martinez, E., Gaytan, S., Ramirez, D., Machado, B., Shindo, P., Martinez, J., Medina, F., Wooten, J., and Ciscel, D., 2011, "Microstructural architecture, microstructures, and mechanical properties for a nickel-base superalloy fabricated by electron beam melting," Metallurgical and Materials Transactions A, 42(11), pp. 3491-3508.

[9] Parthasarathy, J., Starly, B., Raman, S., and Christensen, A., 2010, "Mechanical evaluation of porous titanium $(\mathrm{Ti6A14V)}$ structures with electron beam melting (EBM)," Journal of the mechanical behavior of biomedical materials, 3(3), pp. 249-259.

[10] Murr, L., Esquivel, E., Quinones, S., Gaytan, S., Lopez, M., Martinez, E., Medina, F., Hernandez, D., Martinez, E., and Martinez, J., 2009, "Microstructures and mechanical properties of electron beam-rapid manufactured $\mathrm{Ti}-6 \mathrm{Al}-4 \mathrm{~V}$ biomedical prototypes compared to wrought Ti-6Al-4V," Materials Characterization, 60(2), pp. 96-105.

[11] Sabbadini, S., Tassa, O., Gennaro, P., and Ackelid, U., "Additive manufacturing of gamma titanium aluminide parts by electron beam melting," Proc. TMS 2010 - 139th Annual Meeting and Exhibition, February 14, 2010 - February 18, 2010, Minerals, Metals and Materials Society, pp. 267-274.

[12] Zäh, M. F., and Lutzmann, S., 2010, "Modelling and simulation of electron beam melting," Production Engeering. Research and Development, 4, pp. 15-23.

[13] Mahale, T. R., 2009, "Electron beam melting of advanced materials and structures," Ph.D. thesis, North Carolina State University, Raleigh, NC. 
[14] Jamshidinia, M., Kong, F., and Kovacevic, R., 2013, "Numerical Modeling of Heat Distribution in the Electron Beam Melting® of Ti-6Al-4V," Journal of Manufacturing Science and Engineering, 135(6), p. 061010.

[15] Liu, H., Sparks, T. E., Liou, F. W., and Dietrich, D. M., 2013, "Numerical Analysis of Thermal Stress and Deformation in Multi-Layer Laser Metal Deposition Processes," 24th Annual International Solid Freeform Fabrication Symposium - An Additive Manufacturing Conference, Austin, TX, USA, August 12-14, 2013.

[16] Zaeh, M. F., and Branner, G., 2010, "Investigations on residual stresses and deformations in selective laser melting," Production Engineering, 4(1), pp. 35-45.

[17] Dai, K., and Shaw, L., 2002, "Distortion minimization of laser-processed components through control of laser scanning patterns," Rapid Prototyping Journal, 8(5), pp. 270-276.

[18] Nickel, A., Barnett, D., and Prinz, F., 2001, "Thermal stresses and deposition patterns in layered manufacturing," Materials Science and Engineering: A, 317(1), pp. 59-64.

[19] Matsumoto, M., Shiomi, M., Osakada, K., and Abe, F., 2002, "Finite element analysis of single layer forming on metallic powder bed in rapid prototyping by selective laser processing," International Journal of Machine Tools and Manufacture, 42(1), pp. 61-67.

[20] Jamshidinia, M., Kong, F., and Kovacevic, R., 2013, "The Coupled CFD-FEM Model of Electron Beam Melting ${ }^{\circledR}$ (EBM)," Mechanical Engineering Research, Paper 4.

[21] Vora, P., Stapleton, D., Kamran, M., Derguti, F., Todd, I., and Hopkinson, N., 2012, "Benchmarking Metal Powder Bed Additive Manufacturing Processes (SLM and EBM) to Build Flat Overhanging Geometries Without Supports," 23rd Annual International Solid Freeform Fabrication Symposium - An Additive Manufacturing Conference, Austin, TX, USA, August 68, 2012.

[22] Jhabvala, J., Boillat, E., André, C., and Glardon, R., 2012, "An innovative method to build support structures with a pulsed laser in the selective laser melting process," The International Journal of Advanced Manufacturing Technology, 59(1-4), pp. 137-142.

[23] Yan, C., Hao, L., Hussein, A., and Raymont, D., 2012, "Evaluations of cellular lattice structures manufactured using selective laser melting," International Journal of Machine Tools and Manufacture, 62, pp. 32-38.

[24] Available from: http://software.materialise.com/magics-0.Software for Additive Manufacturing, Materialise. Accessed June, 2012.

[25] Cline, H., and Anthony, T., 1977, "Heat treating and melting material with a scanning laser or electron beam," Journal of Applied Physics, 48(9), pp. 3895-3900.

[26] Marimuthu, S., Eghlio, R., Pinkerton, A., and Li, L., 2013, "Coupled Computational Fluid Dynamic and Finite Element Multiphase Modeling of Laser Weld Bead Geometry Formation and Joint Strengths," Journal of Manufacturing Science and Engineering, 135(1), p. 011004.

[27] Yang, J., Sun, S., Brandt, M., and Yan, W., 2010, "Experimental investigation and 3D finite element prediction of the heat affected zone during laser assisted machining of Ti6Al4V alloy," Journal of Materials Processing Technology, 210(15), pp. 2215-2222.

[28] Rai, R., 2008, "Modeling of heat transfer and fluid flow in keyhole mode welding," Ph.D. thesis, The Pennsylvania State University, State College, PA.

[29] Mills, K. C., 2002, Recommended values of thermophysical properties for selected commercial alloys, Woodhead Publishing.

[30] Cheng, B., Price, S., Lydon, J., Cooper, K., and Chou, K., 2014, "On Process Temperature in Powder-Bed Electron Beam Additive Manufacturing: Model Development and Validation," Journal of Manufacturing Science and Engineering, 136(6), pp. 061018-061018. 
[31] Liu, C., Wu, B., and Zhang, J., 2010, "Numerical Investigation of Residual Stress in Thick Titanium Alloy Plate Joined with Electron Beam Welding," Metallurgical and Materials Transactions B, 41(5), pp. 1129-1138.

[32] Huang, B., Yang, Y., Luo, H., Yuan, M., and Chen, Y., 2008, "Effect of the interfacial reaction layer thickness on the thermal residual stresses in SiCf/Ti-6Al-4V composites," Materials Science and Engineering: A, 489(1), pp. 178-186.

[33] Boyer, R., Welsch, G., and Collings, E. W., 1998, "Materials Properties Handbook: Titanium Alloys," ASM InternationalMaterials Park, OH, USA, pp. 483-636.

[34] Rouquette, S., Guo, J., and Le Masson, P., 2007, "Estimation of the parameters of a Gaussian heat source by the Levenberg-Marquardt method: Application to the electron beam welding," International Journal of Thermal Sciences, 46(2), pp. 128-138.

[35] Mercelis, P., and Kruth, J.-P., 2006, "Residual stresses in selective laser sintering and selective laser melting," Rapid Prototyping Journal, 12(5), pp. 254-265. 
Table 1. Parameter List Used in Simulations.

\begin{tabular}{lr}
\hline Parameters & Values \\
\hline Solidus temperature, $T_{S}\left({ }^{\circ} \mathrm{C}\right)$ & $1605[33]$ \\
Liquidus temperature, $T_{L}\left({ }^{\circ} \mathrm{C}\right)$ & $1655[33]$ \\
Latent heat of fusion, $L_{f}(\mathrm{~kJ} / \mathrm{Kg})$ & $440[33]$ \\
Electron beam diameter, $\Phi(\mathrm{mm})$ & 0.6 \\
Absorption efficiency, $\eta$ & $0.9[34]$ \\
Scan speed, $v(\mathrm{~mm} / \mathrm{sec})$ & 1000 \\
Acceleration voltage, $U(\mathrm{kV})$ & $60[2]$ \\
Beam current, $I_{b}(\mathrm{~mA})$ & 9 \\
Powder layer thickness, $t_{\text {layer }}(\mathrm{mm})$ & 0.07 \\
Porosity, $\varphi$ & 0.5 \\
Beam penetration depth, $d_{P}(\mathrm{~mm})$ & $0.062[12]$ \\
Preheat temperature, $T_{\text {preheat }}\left({ }^{\circ} \mathrm{C}\right)$ & 730 \\
\hline
\end{tabular}



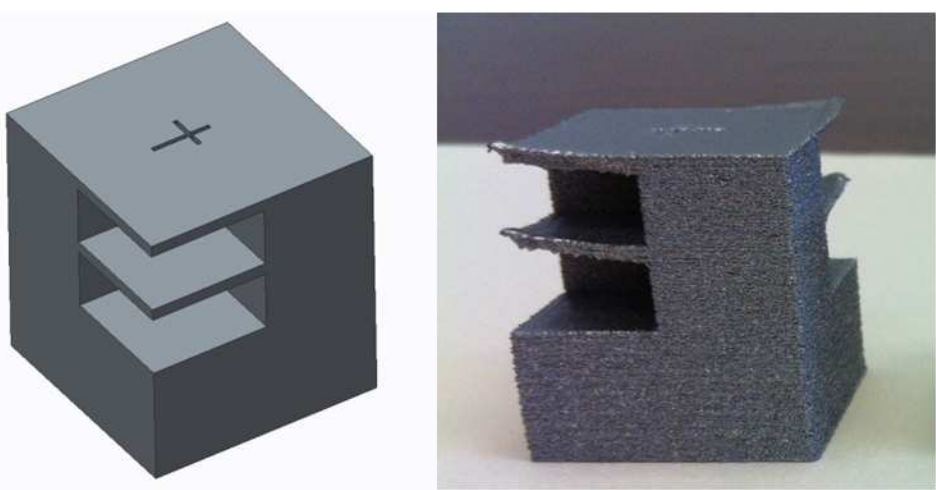

Figure 1. An example of overhang model and associated warping defect. 

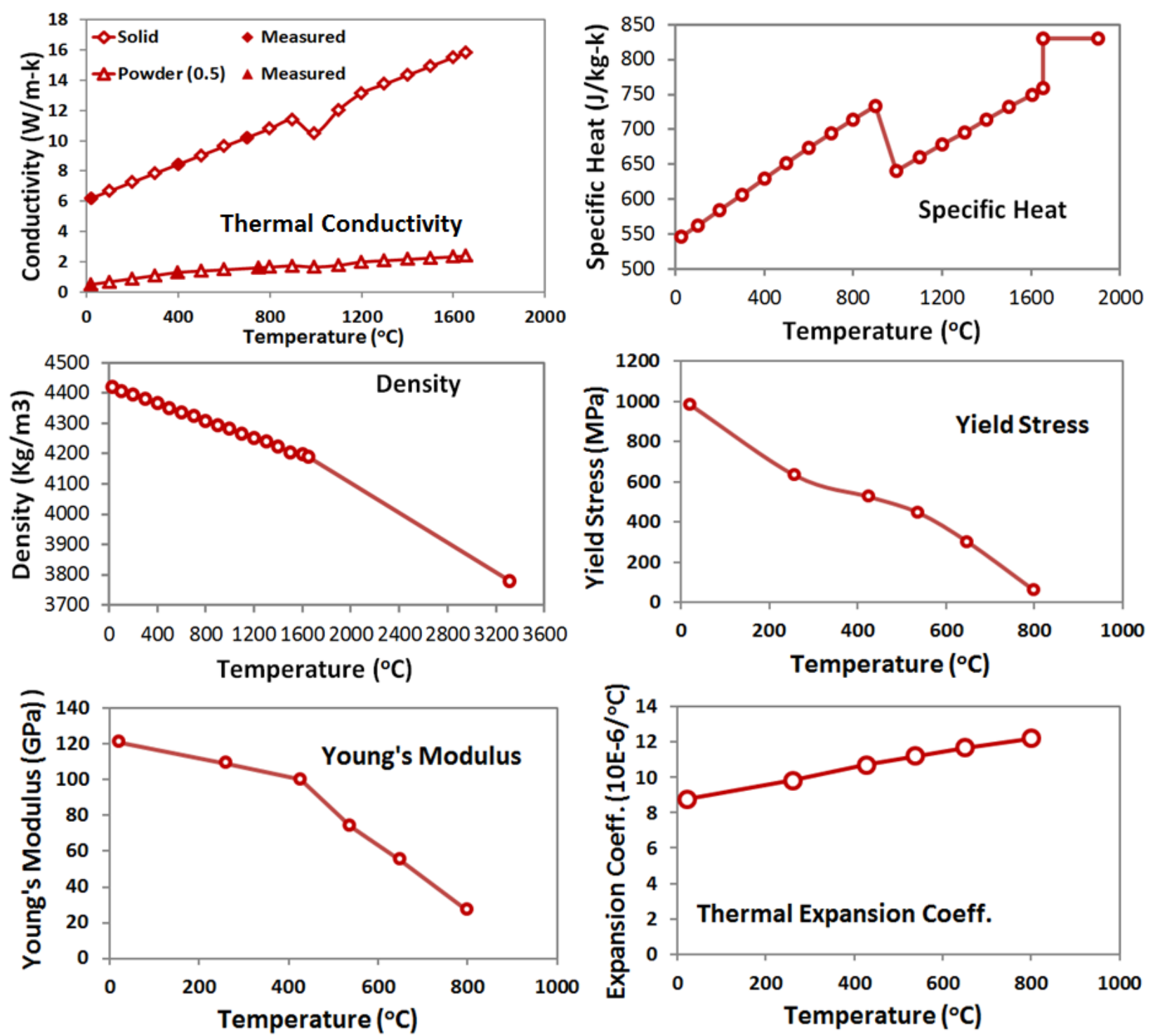

Figure 2. Temperature dependent material properties of Ti-6Al-4V [27-30, 32]. 


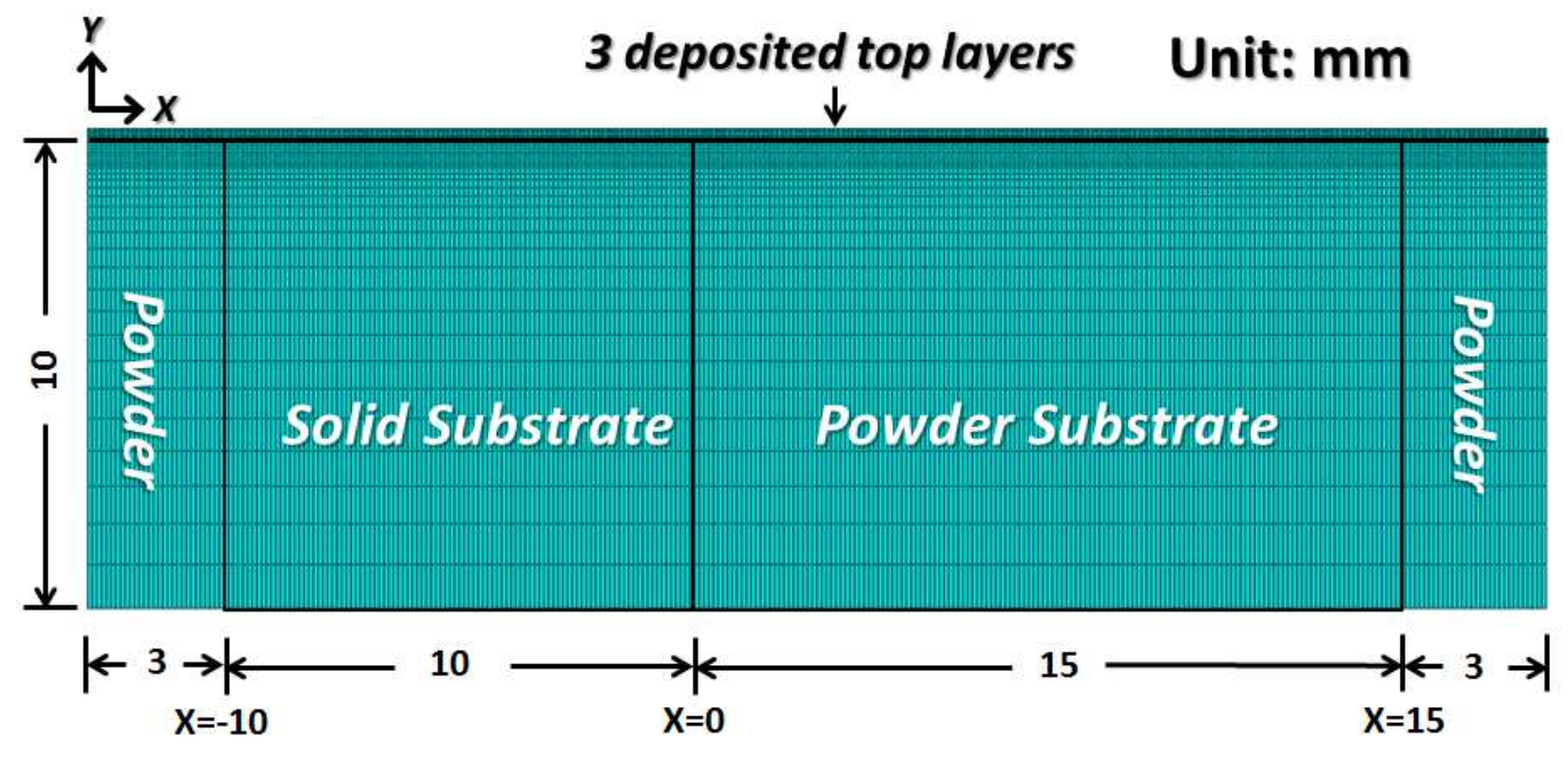

(a)

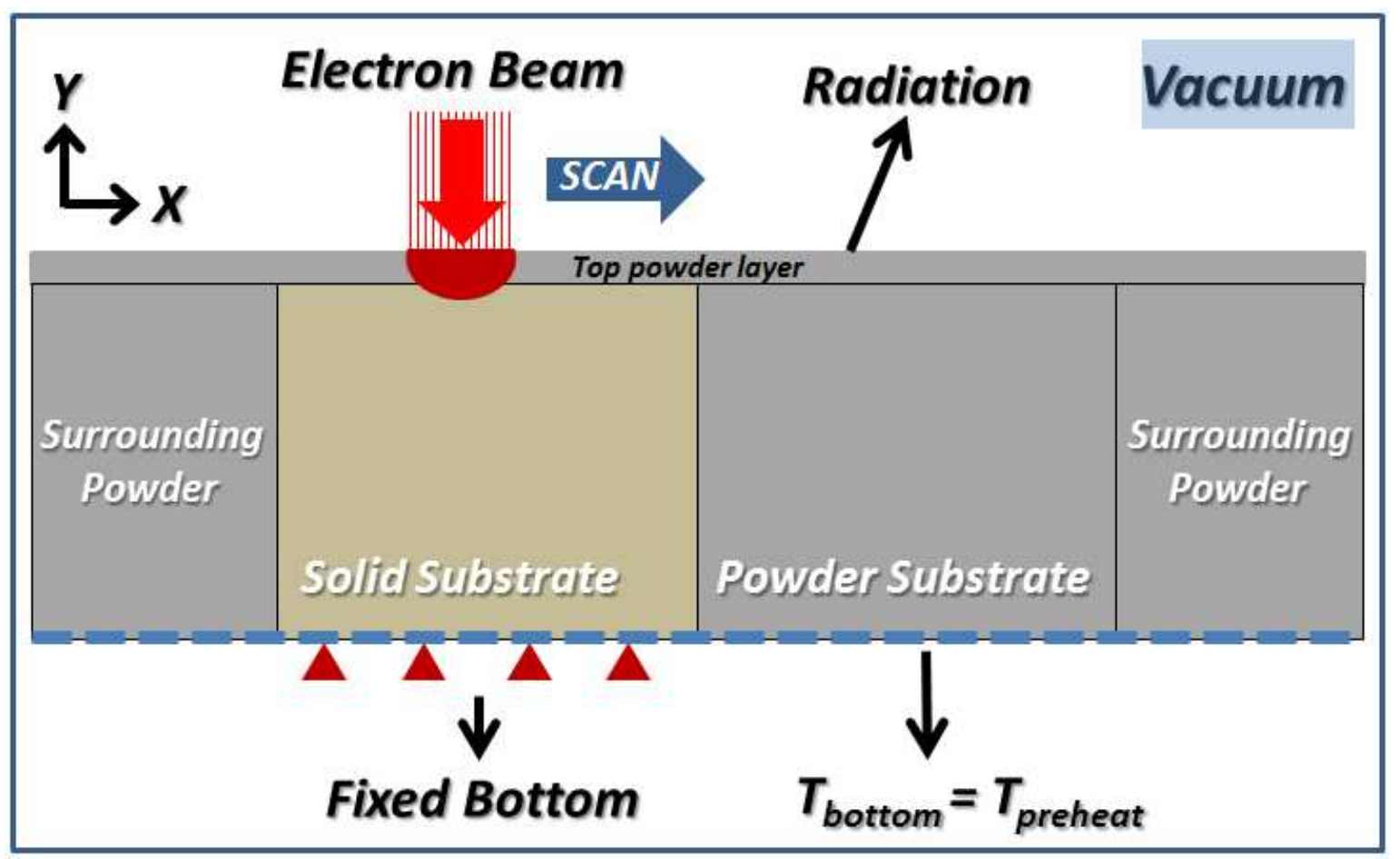

(b)

Figure 3. (a) Model geometric information and (b) Model boundary conditions in electron beam scanning cycle. 


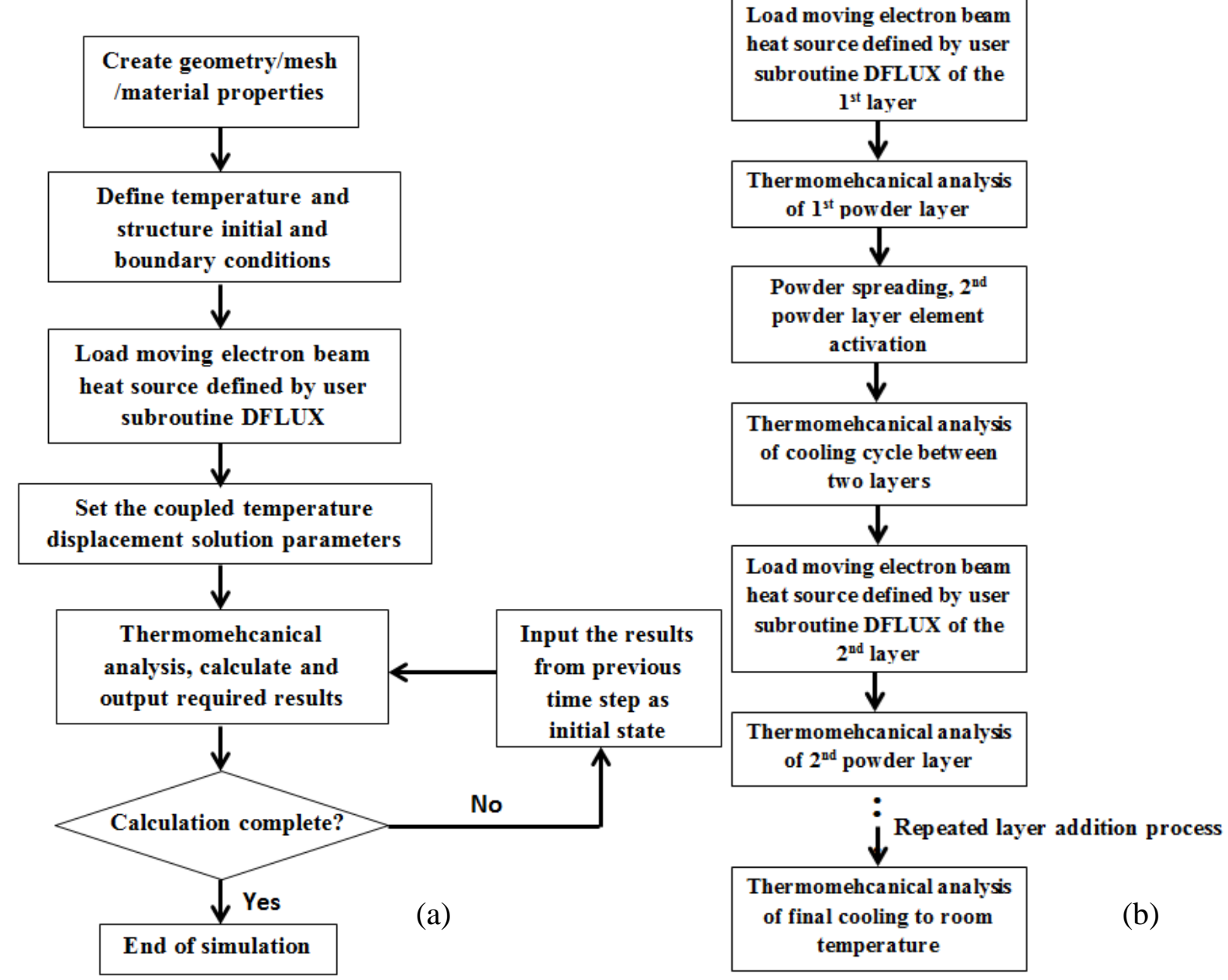

Figure 4. Flow chart of numerical simulation procedure used for the overhang model developed for EBAM: (a) flow chart for thermomechanical simulation; (b) flow chart for multi-layer deposition process. 

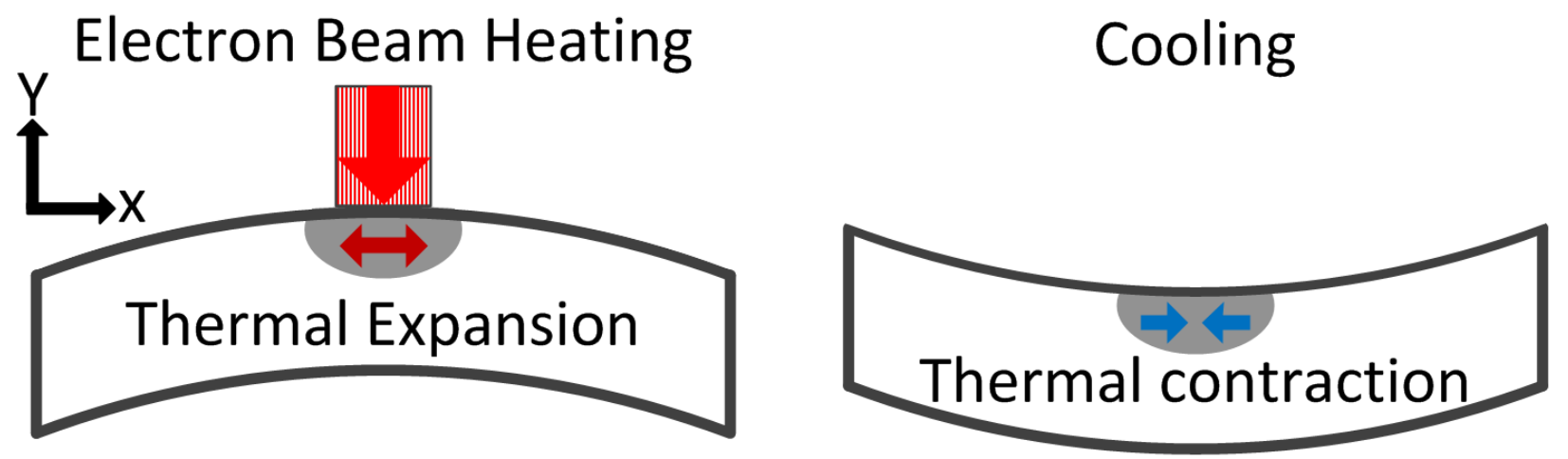

Figure 5. Temperature induced deformation. 


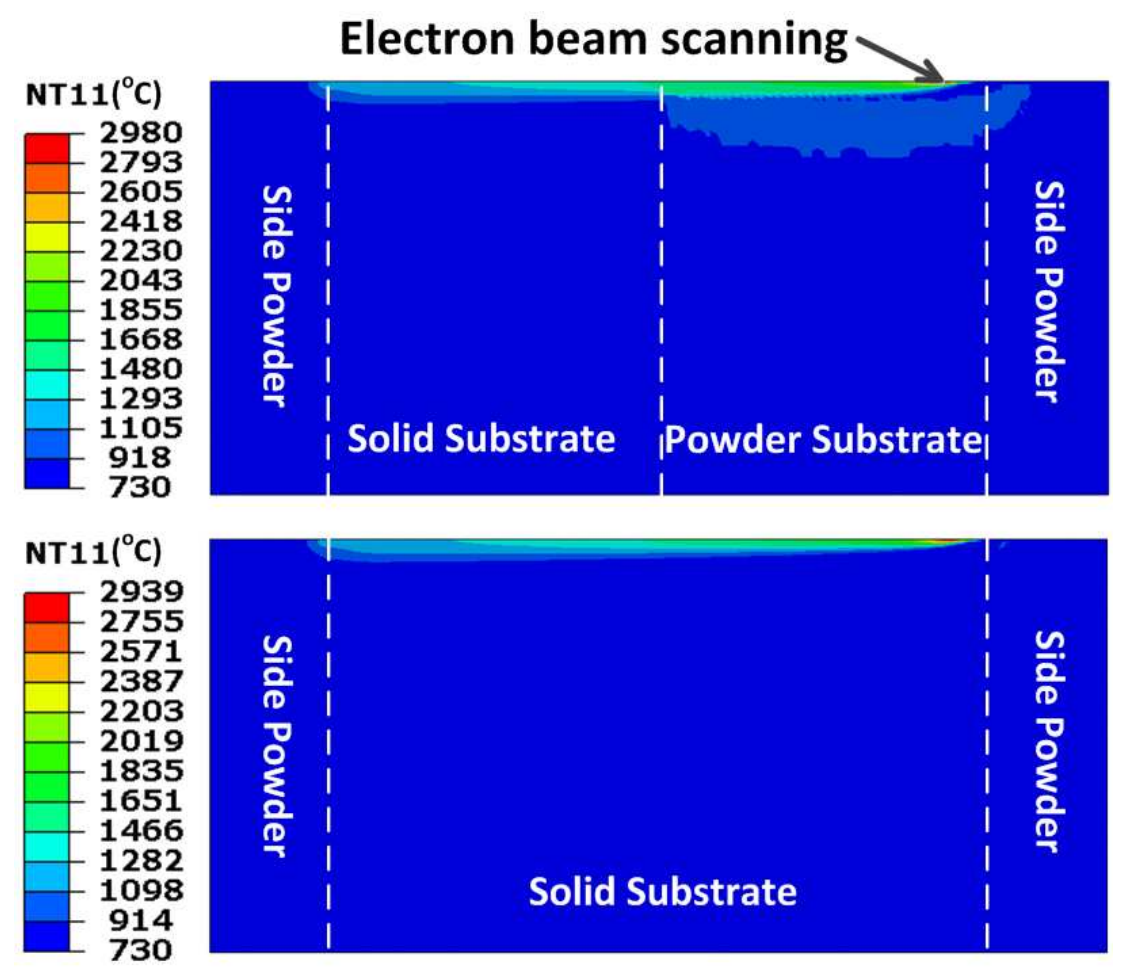

Figure 6. Temperature contours of electron beam scanning on layer-2 for overhang substrate vs. solid substrate cases. 

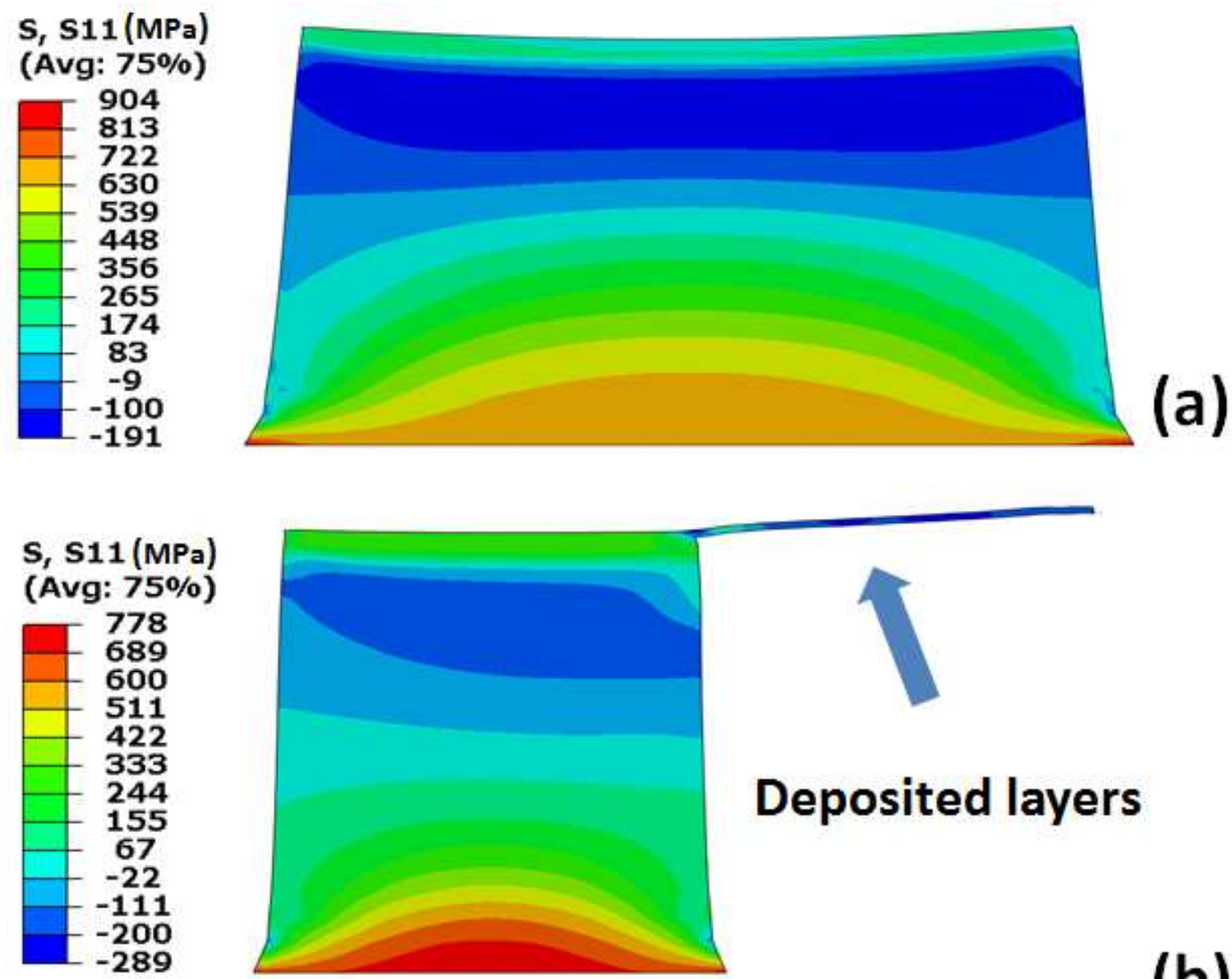

(b)

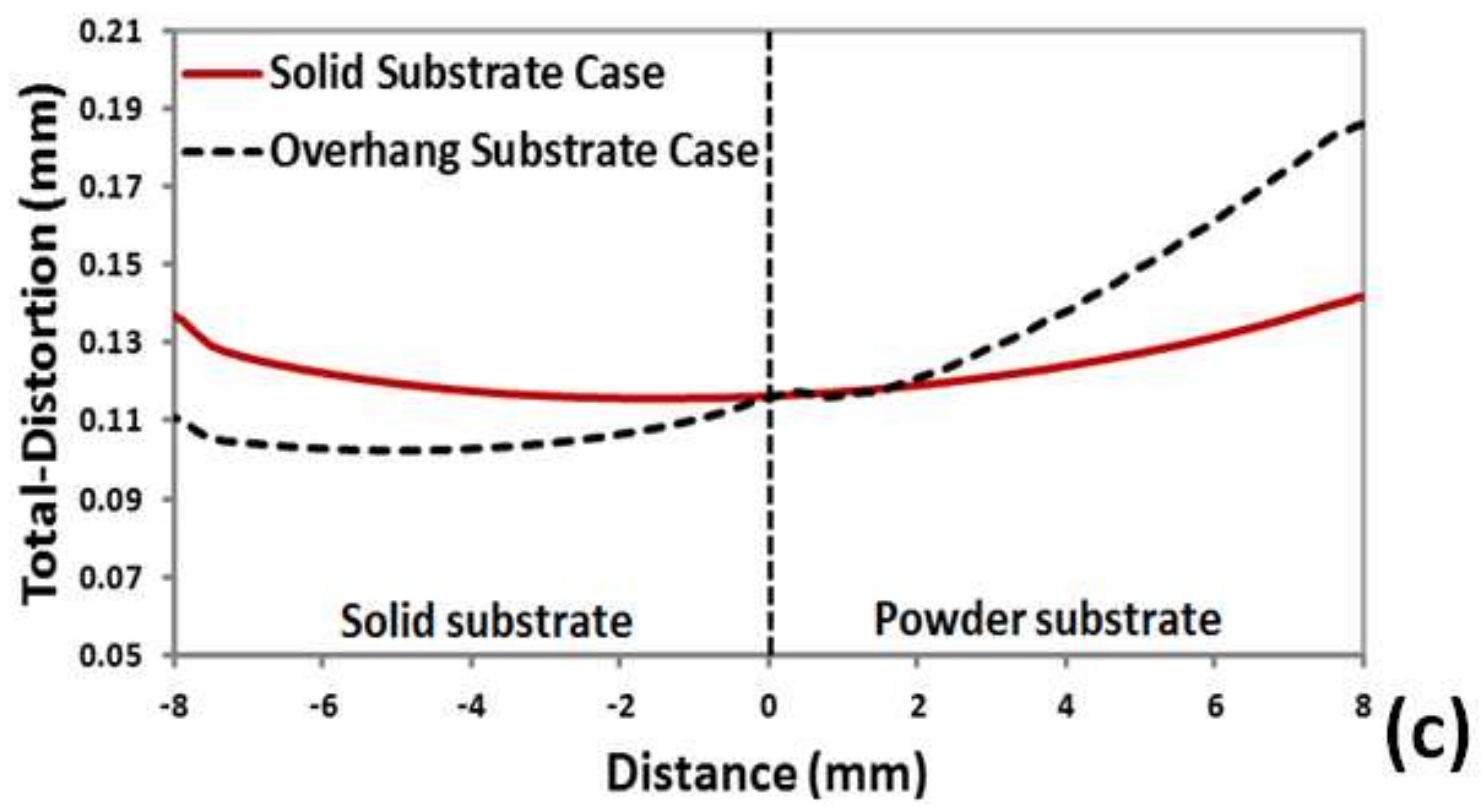

Figure 7. (a) and (b) Typical example of residual stress contours after final cooling (to room temperature); (c) typical example of top surface deformation plots after final cooling. 


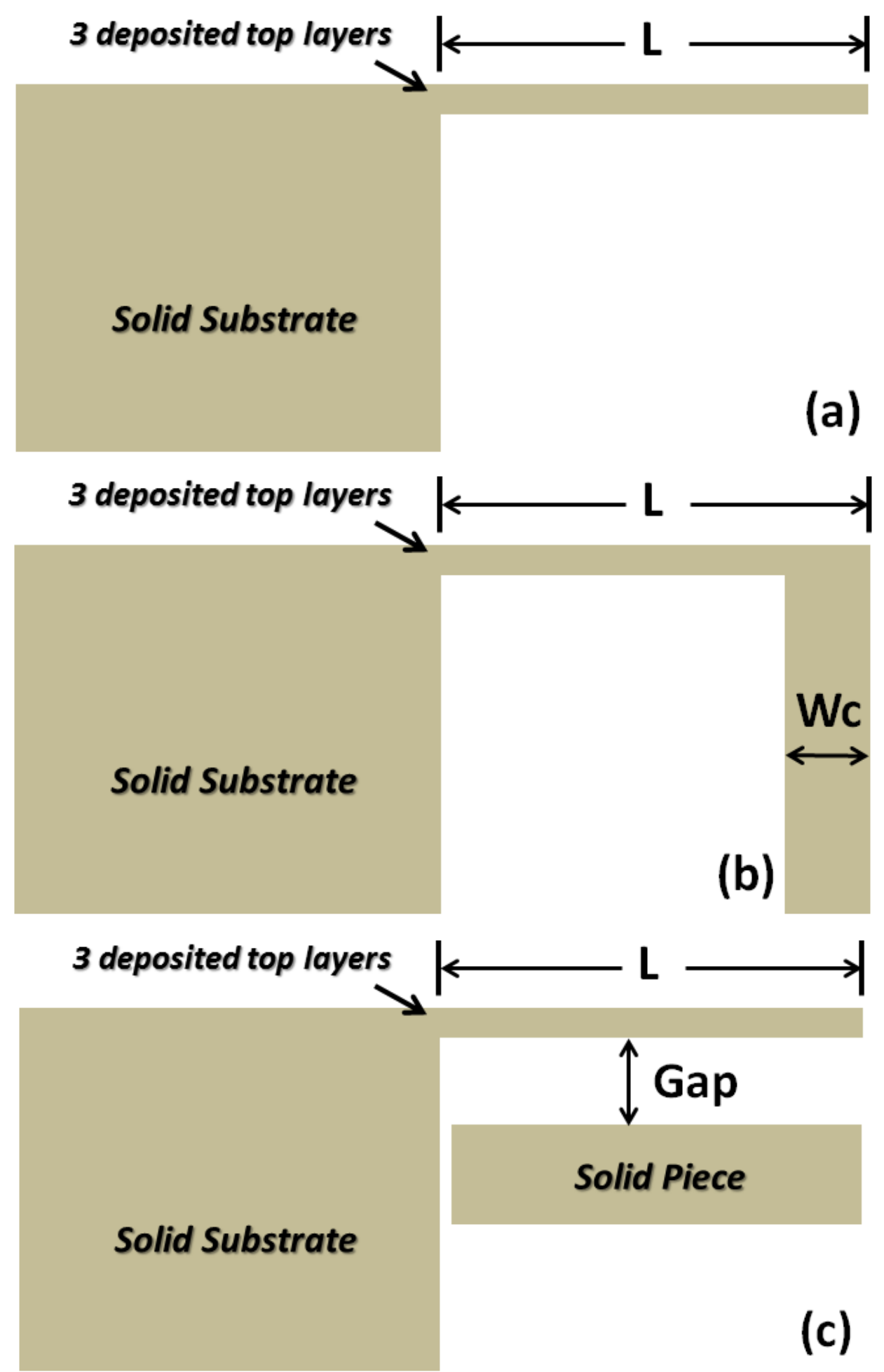

Figure 8. Geometric considerations of different support structures. 


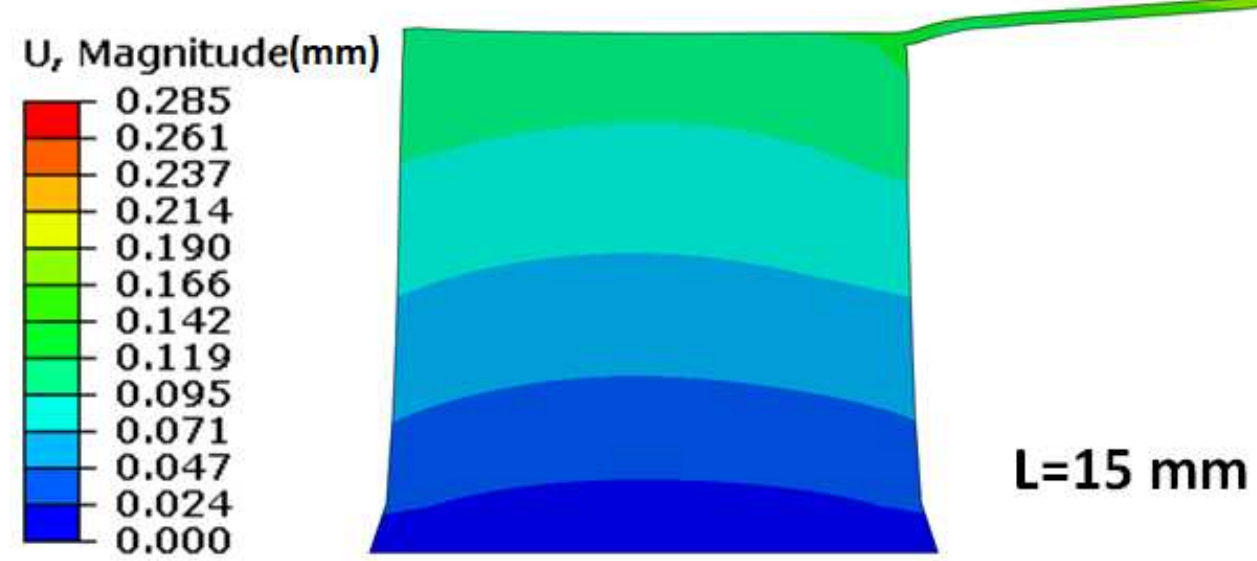

(a)

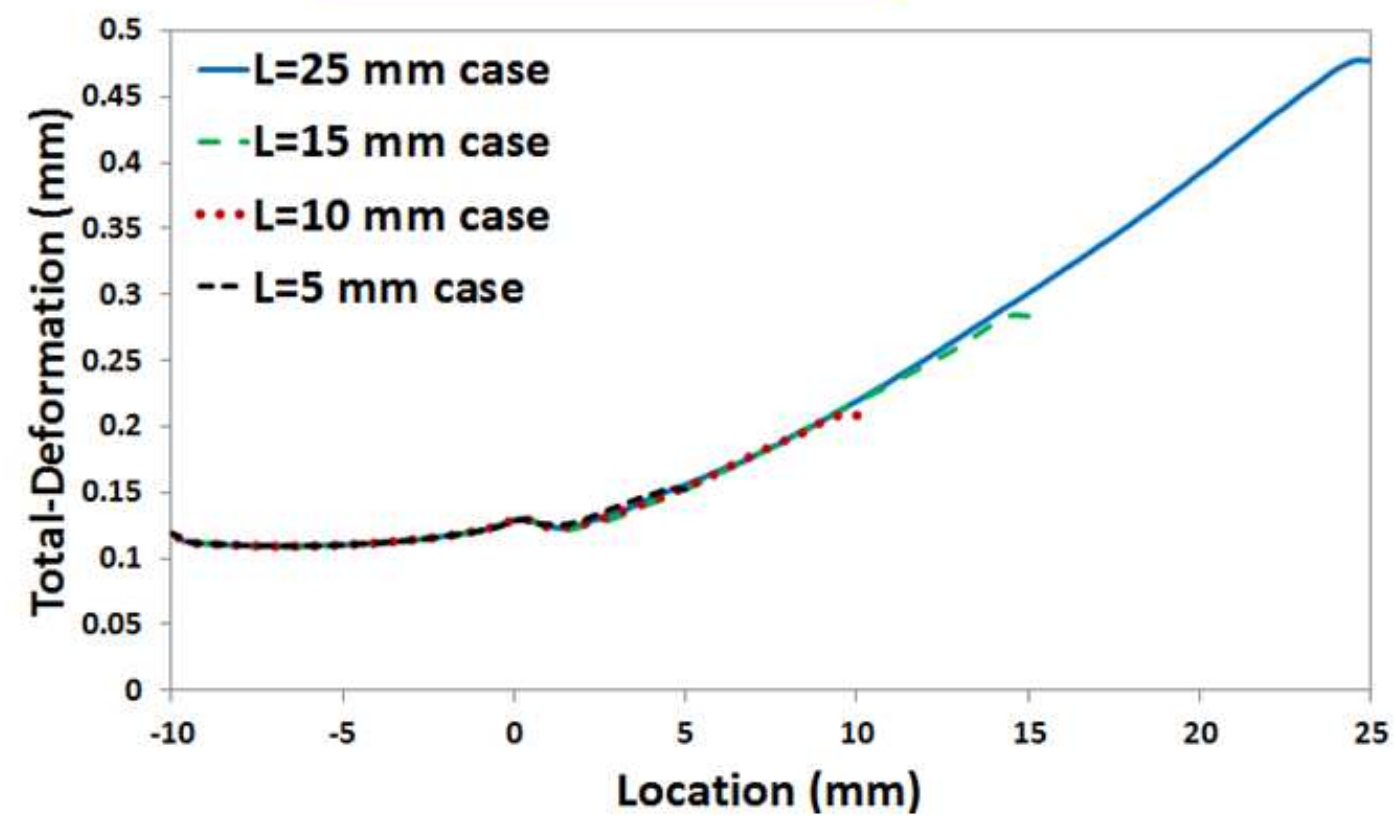

(b)

Figure 9. (a) Typical example of deformation contours after final cooling for overhang length case ( $\mathrm{L}=15 \mathrm{~mm}$ ); (b) different overhang lengths (top surface deformation plots). 

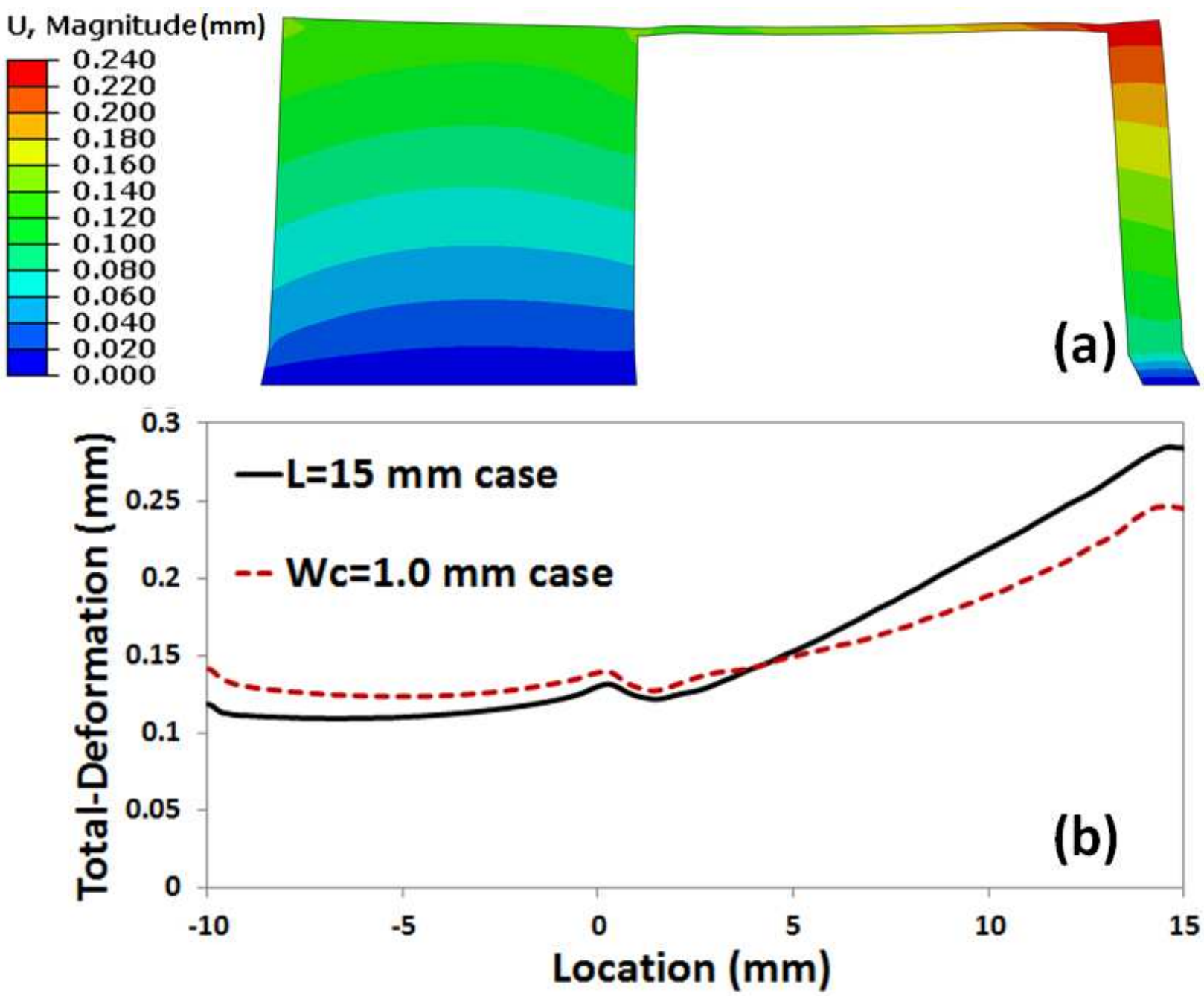

Figure 10. Typical example of deformation contours and top surface deformation plots after final cooling for $\mathrm{Wc}=1.0 \mathrm{~mm}$ case. 


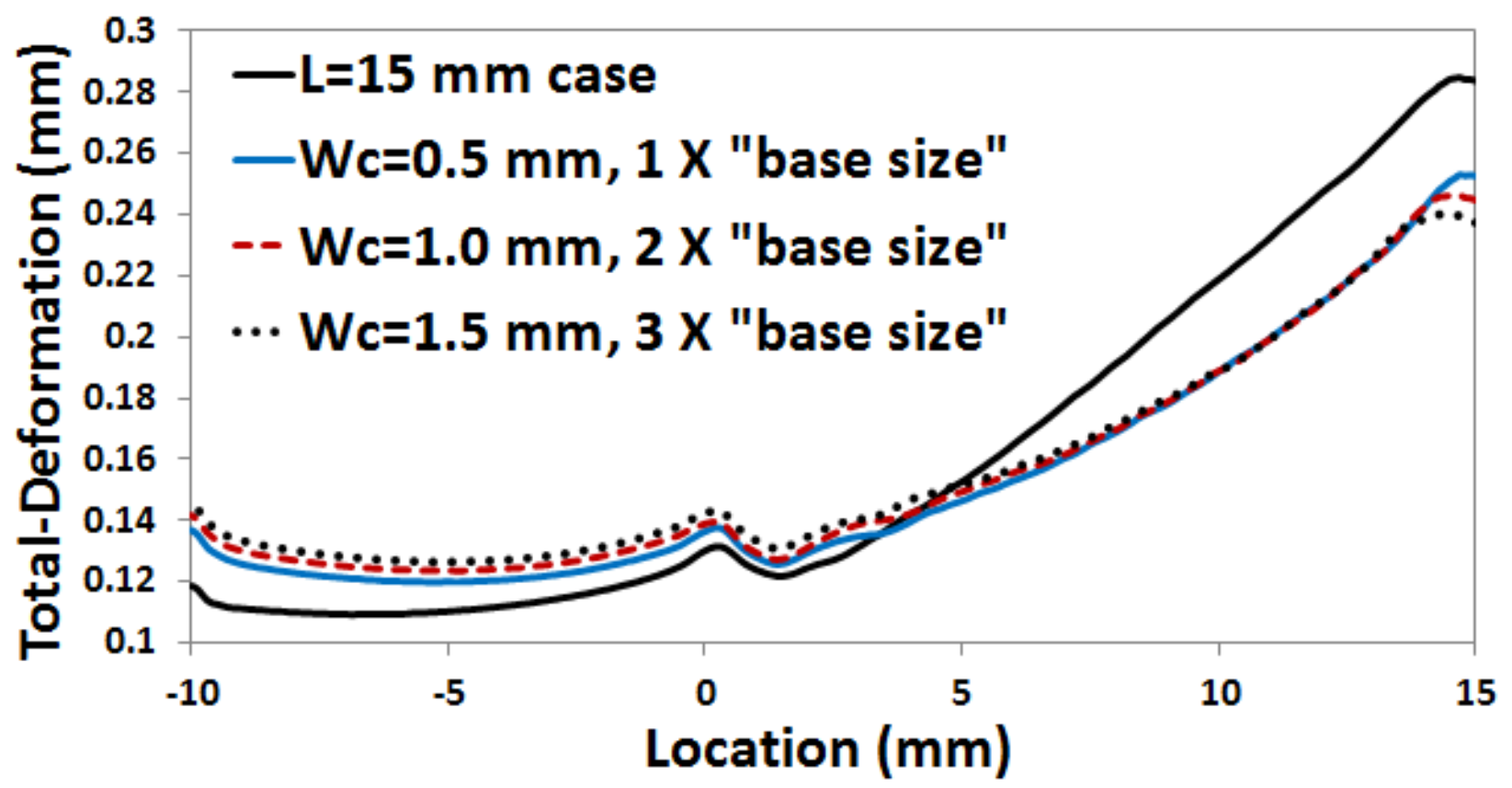

Figure 11. Simulation results comparison of different support column material usage cases (top surface deformation plots). 


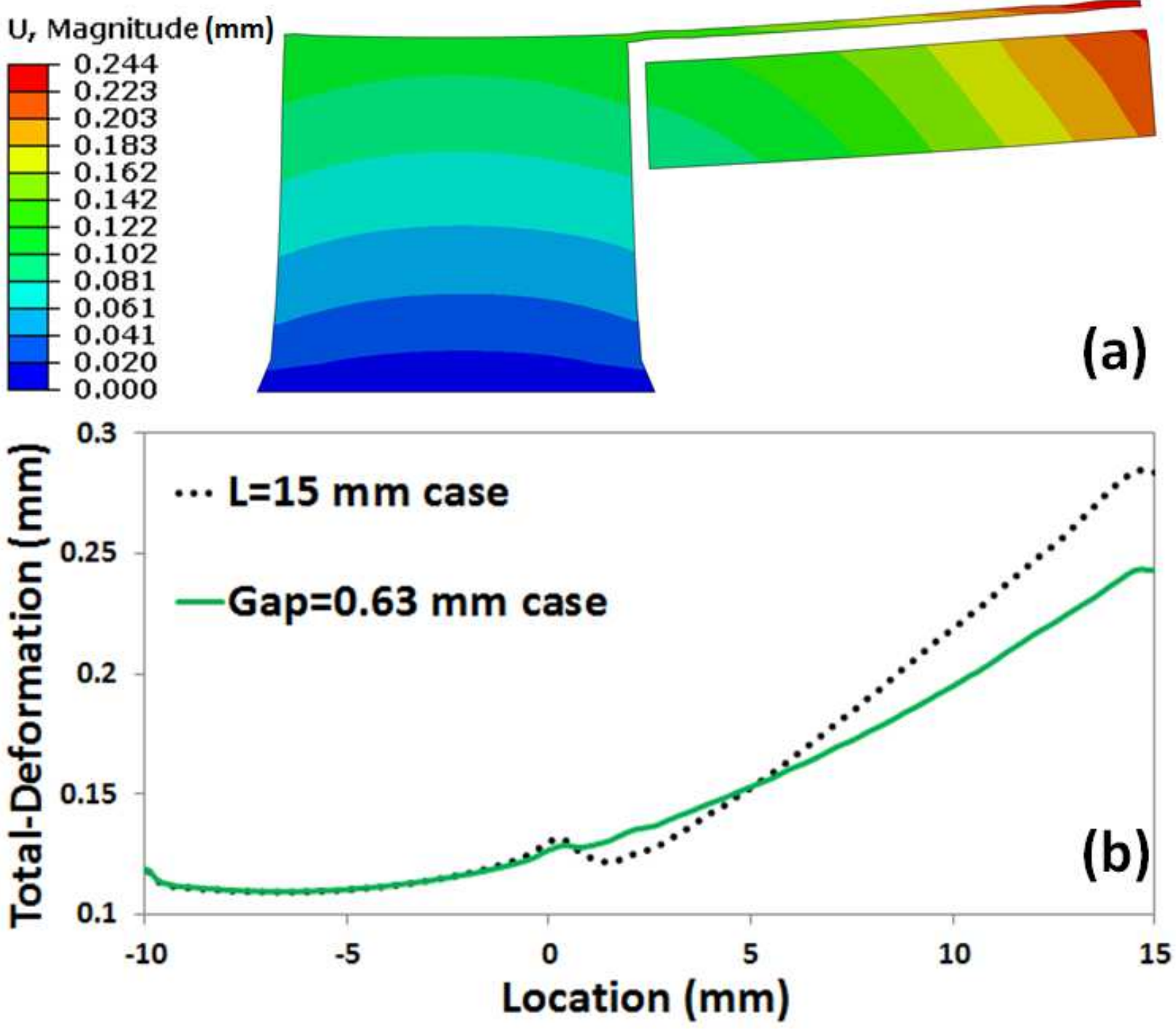

Figure 12. Typical example of deformation contours and top surface deformation plots after final cooling for Gap $=0.63 \mathrm{~mm}$ case. 

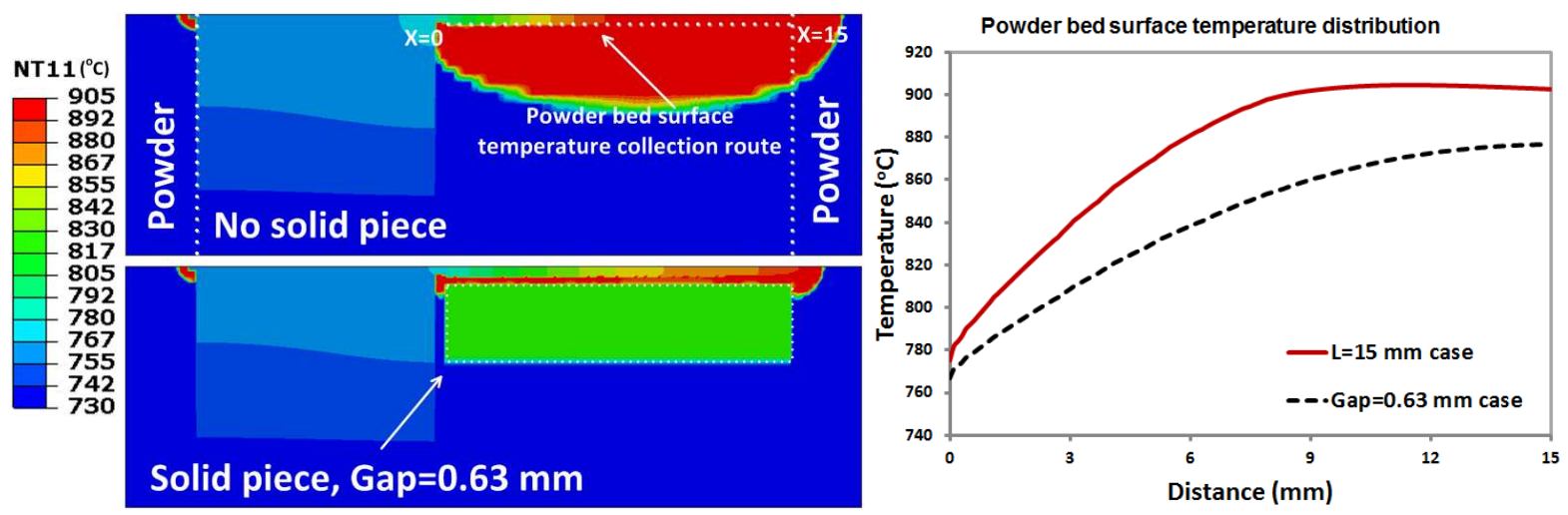

(a)

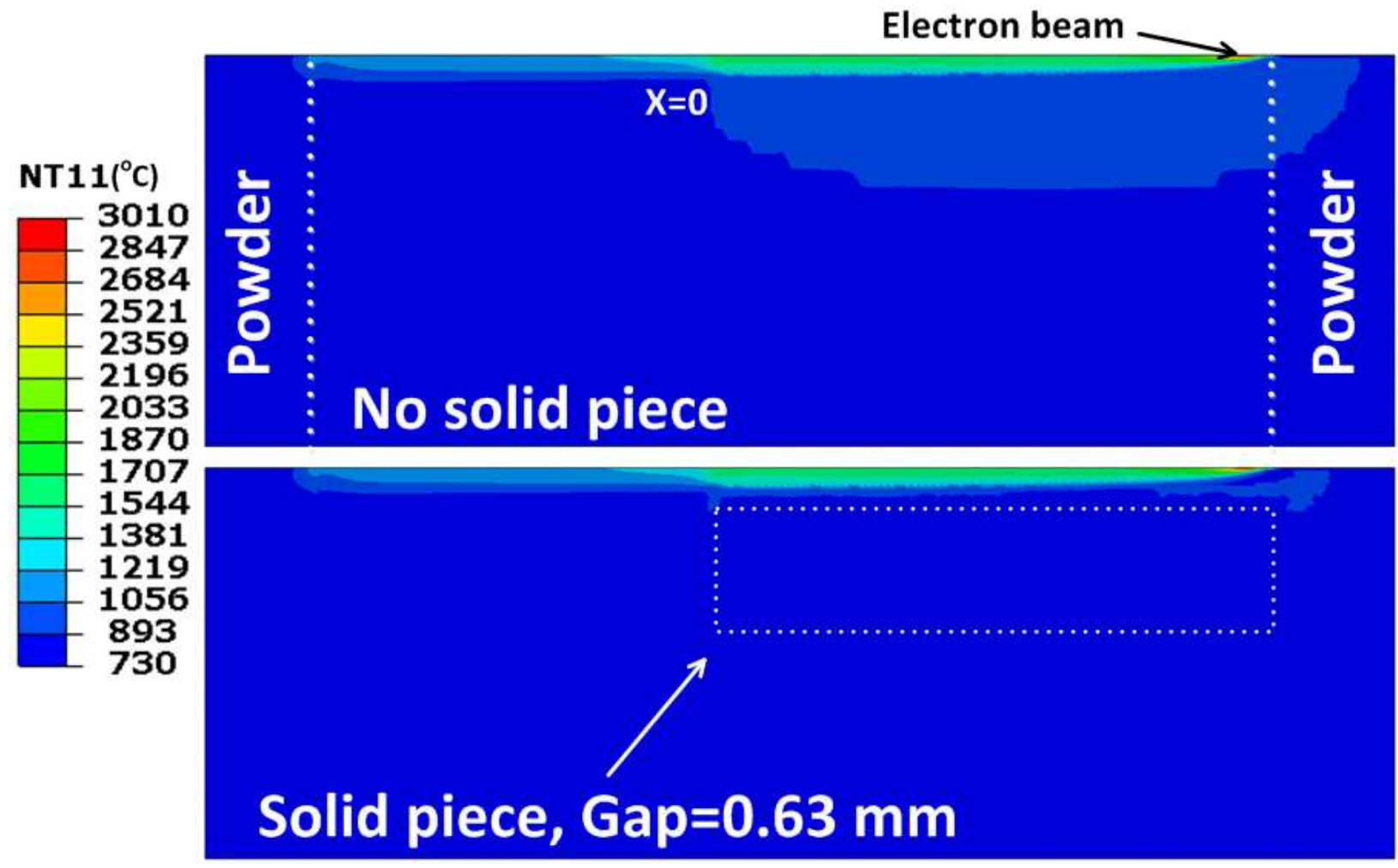

(b) 


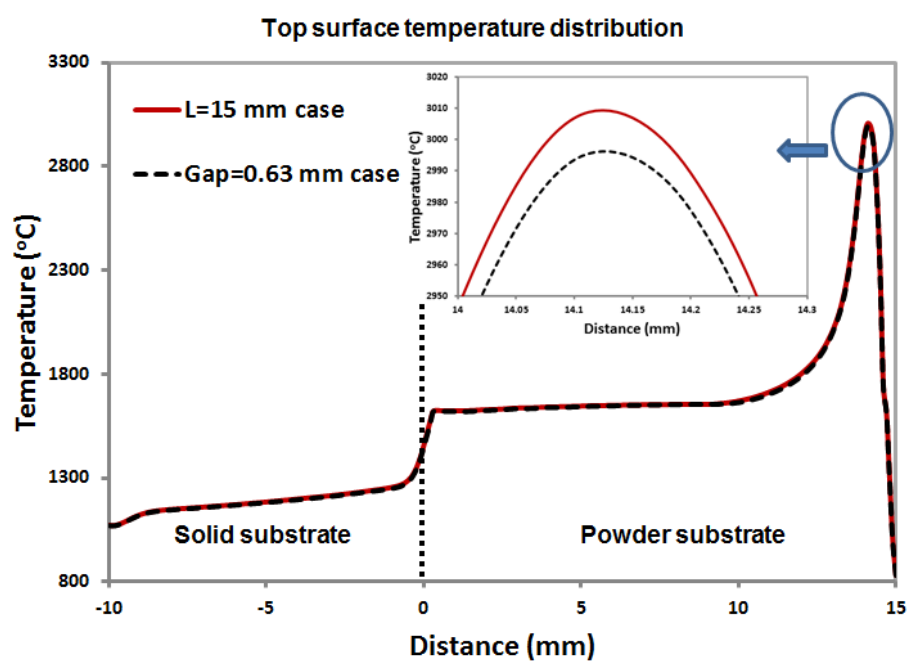

(c)

Figure 13. (a) Typical example of temperature plots (inter-cooling step between layer-2 and layer-3); (b) temperature contours (electron beam scanning on layer-3); (c) deposited layer top surface temperature profiles (electron beam scanning on layer-3). 


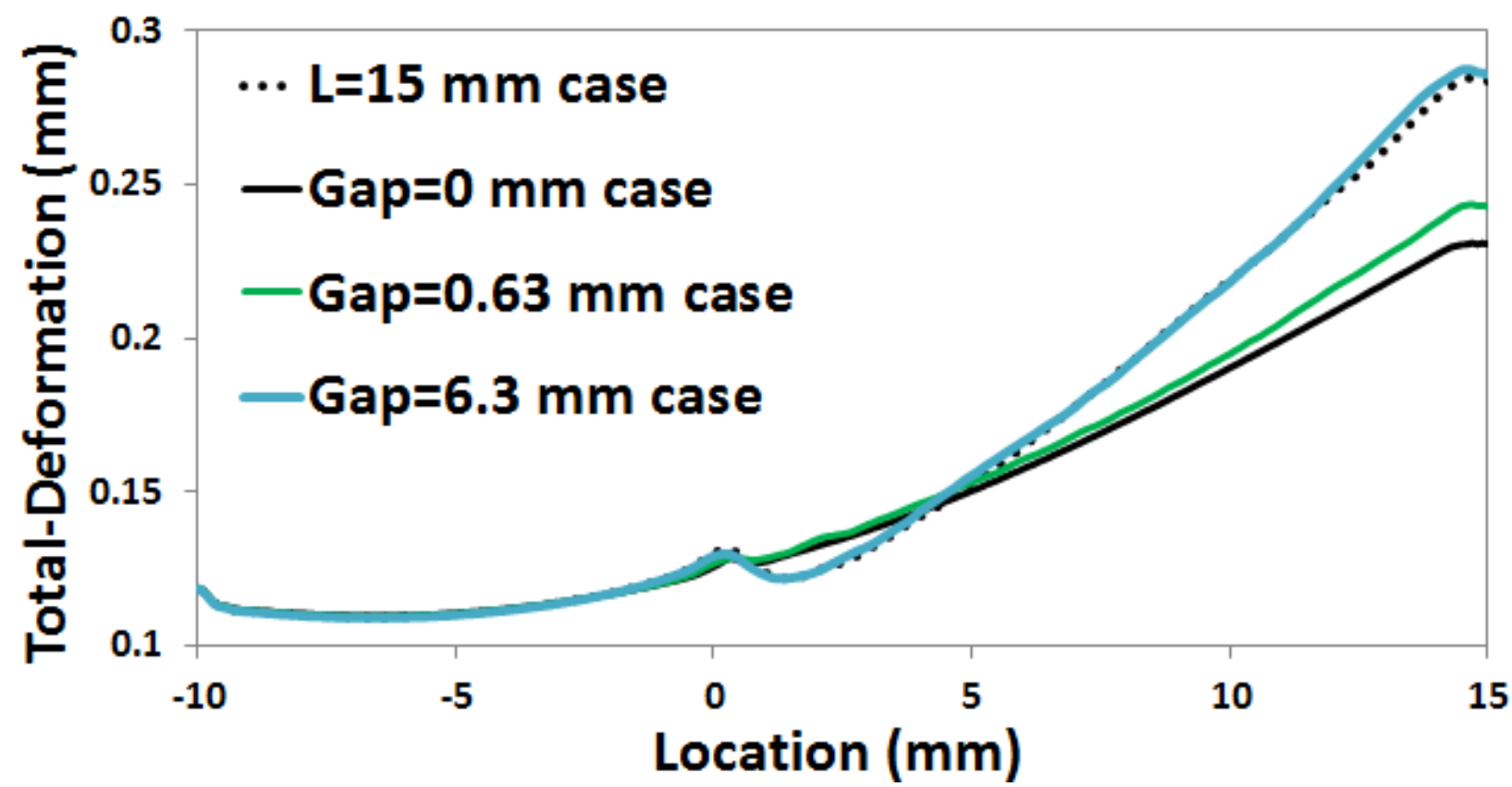

Figure 14. Simulation results comparison of different gap distance cases (top surface deformation plots). 